\title{
Aprofundint en el concepte de transferència d'energia a través de la lectura d'un text
}

\author{
Begonya Oliveras i Neus Sanmartí \\ IES Menéndez y Pelayo, Barcelona \\ bolivera@xtec.cat
}

En aquest article es mostra el desenvolupament d'una activitat, realitzada a $2 n$ d'ESO per treballar el concepte de transferència d'energia a través de la lectura d'un text aparegut en un mitjà no científic, tot desenvolupant diferents competències bàsiques. L'activitat vol promoure alhora el gust per la lectura i la importància de les proves per fonamentar l'argumentació científica.

Paraules clau: lectura de textos, competències bàsiques, contextualització

\section{INTRODUCCIÓ}

Una de les finalitats de la classe de ciències és explicar fenòmens científics per tal d'interpretar el món i la vida real. Però sovint la classe queda desvinculada de tot allò que passa fora, de manera que s'expliquen continguts de forma teòrica, s'apliquen a exercicis inventats i, sovint, repetitius i s'oblida que tot o quasi tot es pot vincular a fets quotidians que l'alumnat viu cada dia. Per això és important ajudar a l'alumnat a fer aquesta connexió.

Pensem que el treball de textos extrets de diferents fonts (diaris, revistes...) amb contingut implícit de ciència pot ajudar a fer aquesta connexió i a la vegada esdevindrà un mitjà per desenvolupar i consolidar algunes competències bàsiques.

La necessitat de potenciar la lectura i la comprensió de textos escrits és palesa des de tots els camps i des de fa molts anys. En el marc educatiu europeu es planteja la lectura com a "comprensió, utilització i reflexió sobre textos per arribar a metes pròpies, desenvolupar coneixements i el potencial propis i per participar en la societat" (OCDE-Pisa, 2000). Des de l'àmbit de les ciències pensem que la lectura autònoma i significativa de tot tipus de textos hauria d'aprendre's en les classes de ciències per permetre a l'alumnat ser capaç de modificar i d'adquirir coneixements al llarg de la vida (Sanmartí, 2003), és a dir, ser competent per aprendre en contextos diferents de l'escolar.
Entenem que aquest aprenentatge és el resultat d'una activitat social compartida. S'ha pogut comprovar (Colomer, 2002) que els alumnes entenen més un text i retenen millor la informació quan el text ha estat analitzat en un grup que quan únicament s'ha treballat individualment. És per aquest motiu que l'activitat plantejada parteix de la realització d'un treball cooperatiu.

Creiem que els textos són una font de dades, informacions i valoracions sobre fets de l'entorn i que la seva lectura comprensiva i crítica possibilita aprofundir en els propis punts de vista, coneixements i valors i reflexionar sobre els fonaments de les actuacions. Al voltant d'una lectura, l'alumnat ha de posar en joc diferents competències que formen un conglomerat inseparable que possibilita actuar de manera reflexiva i responsable, entenent com a competència la "capacitat per aplicar, de manera integrada, coneixements teòrics, habilitats, valors, emocions, experiències... en la comprensió de situacions de l'entorn i en l'actuació responsable". I també "capacitat d'actuar eficaçment i responsablement en situacions diverses, complexes i imprevisibles; comporta mobilitzar sabers de tot tipus, coneixements $i$ també en valors, habilitats, experiència..." (Eurydice, 2002).

Una de les finalitats de l'educació és formar persones autònomes capaces d'analitzar críticament la informació i d'aplicar els coneixements adquirits en situacions diverses. Sovint ens trobem, 


\section{Escalfa, l'abric?}

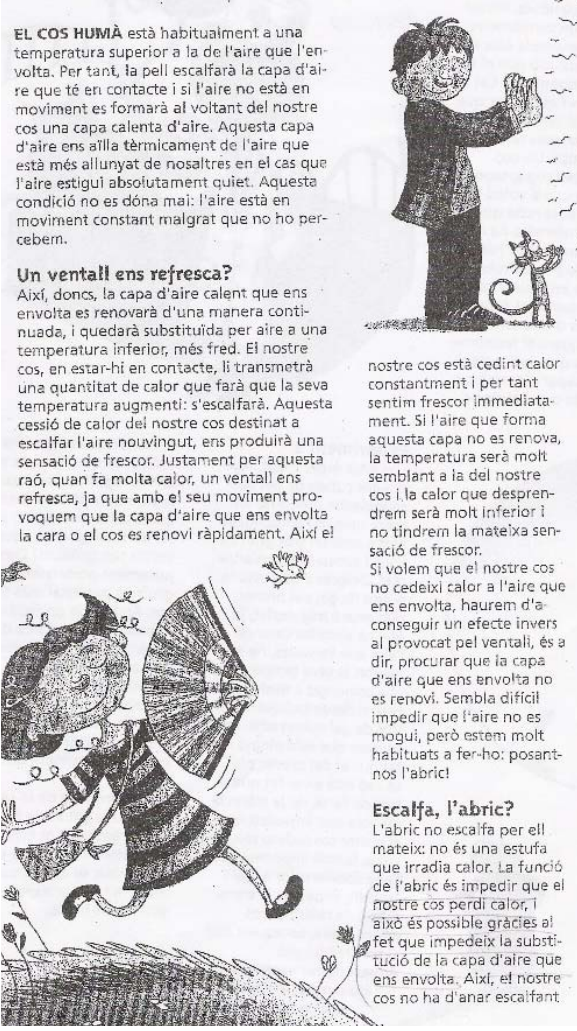

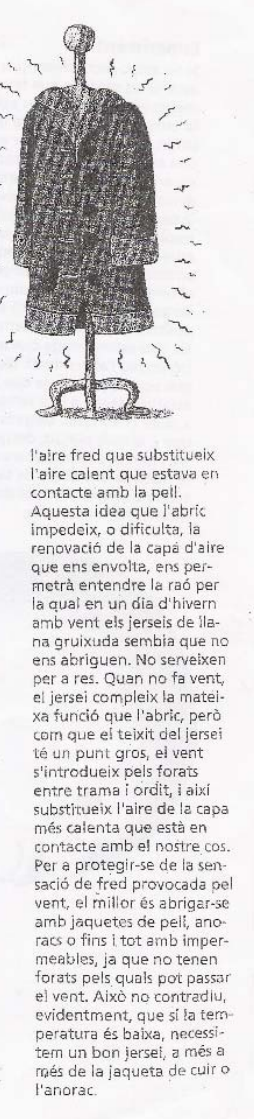

Figura 1. Article "Escalfa, l'abric?". (Disponible a http://phobos.xtec.es/sgfprp/cerca.php) Revista Cavall Fort.

però, que l'alumnat mostra dificultats per analitzar i comprendre fenòmens de la vida quotidiana, tot $i$ disposar dels models científics per entendre'ls.

Probablement el gran repte que tenim com a educadors és que l'alumnat faci aquesta transferència dels coneixements apresos a l'aula a contextos i situacions diferents. Pensem que cal ajudar a l'alumnat a fer aquesta transferència per tal d'interpretar i comprendre els fenòmens de la natura ja que l'escola no pot estar desvinculada del món.

En aquesta línia presentem una activitat realitzada a través de la lectura d'un text d'una revista juvenil, "Cavall Fort". L'article es titula Escalfa, l'abric? (Premi Cavall Fort 2004), i n'és autor Xavier Bohigas i Janoher (fig. 1).

L'escrit explica, d'una manera planera i amena, perquè "no escalfa un abric". Deixa clara la idea que la funció de l'abric és la d'impedir que el nostre cos perdi calor per la substitució de la capa d'aire que ens envolta. Finalment l'article descriu dos experiments senzills que es poden fer a casa per comprovar que l'abric no escalfa i així identificar proves per fonamentar l'argumentació.

\section{CARACTERÍSTIQUES DE L'ACTIVITAT DISSENYADA}

L'activitat es va plantejar com una aplicació dels continguts treballats fins a aquell moment al voltant del concepte de transferència d'energia.

Els objectius proposats pretenien desenvolupar la capacitat de l'alumnat pel que fa a:

1) Aplicar el coneixement que havien començat a construir sobre la transferència d'energia en un context quotidià

2) Escriure un text argumentant les opinions de forma fonamentada

3) Treballar en grup cooperativament

L'activitat descrita va ser aplicada en dues classes de $2 n$ ESO de l'IES Puigvert, de Barcelona durant el curs 2008-2009. En cada classe es van formar grups heterogenis de quatre alumnes triats a l'atzar. En total es van fer 5 grups a cada classe. 


\section{a) Punt de partida}

Per iniciar l'activitat es va demanar a l'alumnat que llegís el títol del text i mirés les imatges, i que individualment definís la paraula "abric".

Després se'ls va demanar que en grup intentessin contestar la pregunta que plantejava l'autor: "Escalfa, l'abric?", i se'ls va proposar que al final de l'activitat elaboressin un text per convèncer a un amic o amiga sobre si un abric escalfa o no.

Per ajudar a elaborar un bon escrit se'ls va donar una pauta per a l'elaboració d'un text argumentatiu, que es compartia a partir de justificar-ne les diferents parts (quadre 1).

\section{Pauta per preparar l'argumentació}

Passos per elaborar un text argumentatiu, en aquest cas concret, sobre el problema

- La meva idea és que

- Les meves raons són

- Convenceria algú que no em creu amb

Evidència que donaria per convèncer els altres

Amb totes dades, ara ja pots redactar un text argumentatiu per defensar la teva idea.

Quadre 1. Activitat "Escalfa, l'abric?". Pauta per preparar el text (Sardà i Sanmartí, 2000)

Per acabar aquesta primera part de l'activitat l'alumnat va conversar en gran grup per intercanviar punts de vista i expressar els diferents arguments inicials.

La finalitat d'aquesta primera part va ser, d'una banda, motivar la lectura del text i, per una altra, detectar si només amb les imatges del text i els seus coneixements previs sobre transferència d'energia l'alumnat es podia representar la finalitat del treball a realitzar i el tipus d'arguments a utilitzar per resoldre la qüestió amb èxit.

\section{b) Lectura de l'article}

Per facilitar-ne la lectura es va dividir el text en cinc parts ben diferenciades i amb entitat pròpia. L'alumnat va llegir cada part i cooperativament va buscar la idea principal.

Cada grup es va autorregular elegint el mètode que els va semblar més eficient per buscar la idea principal.

\section{c) Treball posterior a la lectura}

Quan l'alumnat va haver llegit i escrit les idees principals de cada part se'ls va demanar que tornessin a respondre la pregunta inicial "Escalfa l'abric?", tot seguint la pauta de text argumentatiu (quadre 1).

En grup van comparar les seves propostes i les van enriquir per escriure el redactat final de cada part . Posteriorment van escriure un text argumentatiu. Dies després se'ls va demanar que tornessin a definir la paraula "abric", però ara de manera individual.

\section{RESULTATS}

Cal remarcar que les respostes de l'alumnat abans de llegir l'article i després foren molt diferents.

Abans de la lectura de l'article la majoria dels grups (9 de 10) opinava que un abric escalfava $i$ donaven raons col-loquials tant per argumentar la seva idea (perquè no tenim fred quan ens el posem, perquè porta materials gruixuts, perquè sense l'abric passem fred o senzillament deien que a l'estiu ningú porta abric), com per convèncer als altres (provar de no portar l'abric a l'hivern).

Després d'haver llegit l'article, els grups que pensaven que l'abric escalfava canviaven radicalment d'opinió. En el text argumentatiu final es veu que hi ha un canvi en els tipus d'arguments i contra-arguments que citen, utilitzant un vocabulari més científic. En les argumentacions finals l'alumnat dóna raons científiques per argumentar la seva idea (Aïlla el nostre cos del fred i del calor, conserva la calor; es pot demostrar científicament; impedeix o dificulta renovar la capa d'aire que ens envolta o que l'abric no escalfa que el que fa és que la temperatura del cos no surti a l'exterior i el fred no passi a l'interior) i també utilitzen la ciència per convèncer (donant bons arguments $i$ amb experiments). Cal remarcar que la majoria de l'alumnat considera que l'evidència és el resultat de l'experiment. 
Sens dubte els arguments utilitzats són molt millorables, així com l'escriptura del text, i segurament hagués estat útil promoure una coavaluació final perquè s'ajudessin a millorar-la, però donat els punts de vista inicials expressats i que era la primera activitat d'aquest tipus que realitzaven, valorem que els avenços van ser importants.

Exemple de text argumentatiu elaborat per un dels grups:

\section{L'abric, escalfa?}

La nostra idea és que l'abric no escalfa, sinó que conserva la calor corporal del qui el porta, ja que està demostrat científicament.

La majoria de gent diria que l'abric escalfa però això és incorrecte. Ja que si posem uns cubs de gel dins d'un drap $i$ uns altres al costat durant una estona, veurem que els cubs de gel s'han mantingut millor quan estaven embolicats amb el drap. Amb això arribem a la conclusió de que l'abric ens aïlla del calor $i$ del fred segons la temperatura ambiental que ens envolta.

\section{Conclusions}

Plantejar la pregunta "Escalfa, l'abric?" abans de la lectura ha actuat de motivació. Tots han tingut curiositat per llegir el text i buscar-hi la resposta.

També es pretenia comprovar si sabien relacionar el títol i les imatges de l'article amb els seus coneixements sobre transferència d'energia a una situació quotidiana. Un cop analitzades les respostes s'ha vist que una bona part del estudiants no establien cap relació.

El fet que s'hagi fomentat la co-regulació i l'auto-regulació en la lectura del text, creiem que ha contribuït a la seva bona comprensió. Una lectura només individual no ho hauria afavorit.

Pel que fa a saber argumentar a favor o en contra de les seves conviccions primeres, volem fer constar que els ha estat molt útil la pauta d'argumentació que els hem facilitat, ja que els ha ajudat a organitzar les idees $\mathrm{i}$ ha donat contingut al seu text. Aquesta pauta també ens ha estat útil per comprovar el canvi d'arguments i d'evidències entre una redacció anterior i posterior a la lectura del text.

Abans de la lectura del text la majoria de l'alumnat opinava que l'abric sí que escalfava, i cap d'ells utilitzava conceptes estudiats recentment per justificar-ho (transferència d'energia) ni parlaven de la propietat de ser aïllant tèrmic, tot i haver realitzat pràctiques en aquesta línia.

Un cop realitzada l'activitat, tots els nois i noies havien canviat la seva definició primera i havien incorporat en els seus textos la idea de transferència d'energia.

El fet de fer-los definir la paraula abric, abans de la lectura i dies després de fer-la, ens ha permès demostrar que hi ha hagut una interiorització del concepte i, per tant, que l'activitat ha ajudat a assolir el concepte de transferència d'energia que era un dels objectius que ens plantejàvem. Abans de la lectura l'alumnat donava definicions del tipus "I'abric és una peça de roba que es porta a l'hivern" o "l'abric és una peça de roba que es porta quan fa fred per no passar fred", i en canvi, dies després de l'activitat eren capaços d'escriure frases del tipus: "peça de roba que no deixa que la calor corporal se'n vagi" o "peça de roba que no deixa que el calor corporal es transfereixi a l'ambient".

Aquesta activitat pot servir d'exemple per treballar algunes competències bàsiques del currículum. La competència científica, ajudant a l'alumnat a construir el concepte de transferència d'energia, la competència comunicativa $i$ lingüística, ajudant a l'alumnat a emetre opinions argumentades i buscant estratègies per comprendre el text (seleccionant la idea principal de cada paràgraf, discutir en grups aquestes idees...), la competència d'autonomia personal, aprenent a autorregular-se, i la competència d'aprendre a aprendre, imaginant respostes a la pregunta del text abans de la lectura, treballant en equip i compartint el saber amb els altres.

Per tant, considerem que el treball de textos de diferents fonts (diaris, revistes, articles de divulgació científica...) a classe pot ajudar a millorar la comprensió d'alguns dels fenòmens que estudiem a l'aula i, a la vegada, a la seva connexió amb el món, tot desenvolupant competències bàsiques del currículum.

Val a dir que l'alumnat en tot moment s'ha mostrat molt engrescat en l'activitat, fins i tot aquells alumnes que normalment no treballen. En finalitzar l'activitat demanaven quan en farien una altra de similar.

\section{Bibliografia}

COLOMER, T. (2002). La enseñanza y el aprendizaje de la comprensión lectora. En: Lomas,C. (comp.) El aprendizaje de la comunicación en las aulas. Barcelona: Ed.Paidós.

DA SILVA, C. i ALMEIDA, M.J. (1998). Condicoes de produçao da leitura em aulas de física no ensino médio: um estudo de caso. En: Almeida, M.J. y Da Silva, C. (edit.) Linguagens, leituras e 
ensino da ciencias. Campinas: Associaçao de Leitura do Brasil.

EURYDICE (2002) Las competencias clave. Madrid: MECD, 12-14.

MARBÀ,A., MÁRQUEZ,C. i SANMARTí, N. (2009). ¿Qué implica leer en clase de ciencias? Reflexiones y propuestas. Alambique, 59, 102-111.

MÁRQUEZ, C. i PRAT, A. (2005). Leer en clase de ciencias. Enseñanza de las Ciencias, 23 (3), 431-440.

OECD (2000). Mesuring student knowledge and skills. The PISA 2000. Assessment of Reading, Mathematical and Scientific Inquiry. Paris: OECD Pub. Service.
OLIVERAS, B. i SANMARTÍ, N. (2008). Treballant les competències en la classe de Química. Educació Química, 1.

SANMARTÍ, N. (2003). Ensenyar ciències a partir d'un currículum fonamentat en el desenvolupament de competències bàsiques. Actes Congrés de competències bàsiques. Barcelona: Departament d'Ensenyament.

SARDÀ, A. i SANMARTí, N. (2000). Ensenyar a argumentar científicament: un repte de les classes de ciències. Enseñanza de las Ciencias 18 (3), 405-422. 